\title{
FUNGSI TRADISI LISAN AURODAN DARI TAREKAT ASY-SYAHADATAIN CIREBON DALAM KEHIDUPAN KOMUNITAS PEMILIKNYA
}

\section{ORAL TRADITION AURODAN FUNCTION IN CIREBONESE ASY- SYAHADATAIN IN COMMUNITY'S LIFE}

\author{
Ahmad Maskur Subaweh ${ }^{1 *}$, Sumiyadi², Iskandarwassid ${ }^{3}$, T. Permadi ${ }^{4}$ \\ PBI Pascasarjana, UPI Bandung, Indonesia ${ }^{1,2,3,4}$, \\ $\underline{\text { ahmadmaskur4@gmail.com }}^{1}$, sumiyadi@upi.edu $^{2}$, iskandarwassid@upi.edu $^{3}$, \\ tedipermadi@upi.edu ${ }^{4}$ \\ *penulis korespondensi
}

\begin{tabular}{ll}
\hline Info Artikel & ABSTRAK \\
\hline Sejarah artikel: & Tradisi Aurodan Jamaah Tarekat Asy-Syahadatain di Cirebon adalah \\
Diterima: & bagian dari tradisi lisan dalam bentuk ritual pertunjukan, yang merupakan \\
8 Mei 2020 & zikir berbunyi nyaring bersama dengan nyanyian puisi nadhoman Cirebon. \\
Direvisi: & Aurodan mencerminkan budaya Islam Cirebon yang lembut, terbuka, dan \\
24 Juni 2020 & toleran sebagai produk akulturasi dari beberapa budaya, yaitu Jawa, Sunda, \\
Disetujui: & Arab, dan bahkan budaya lain di Cirebon. Penelitian ini bertujuan untuk \\
22 Juli 2020 & mendeskripsikan fungsi tradisi lisan Aurodan komunitas Jamaah Asy- \\
& Syahadatain di Cirebon. Penelitian ini adalah penelitian kualitatif yang \\
Kata kunci: & meneliti objek dalam kondisi alam, untuk menemukan makna dan \\
Tradisi lisan, Aurodan,, & generalisasi, di mana peneliti sebagai instrumen utama dalam metode \\
fungsi, Asy- & penelitian. Penelitian ini dirancang untuk menggambarkan, menganalisis, \\
Syahadatain Cirebon & mengungkap, dan menjelaskan fungsi tradisi Aurodan Asy-Syahadatain \\
& Cirebon. Penelitian ini menggunakan data dasar yaitu fungsi tradisi lisan \\
& Aurodan Asy-Syahadatain Cirebon. Pengumpulan data tenik dilakukan \\
& dengan observasi, wawancara, studi dokumen. Hasil penelitian ini \\
& menemukan beberapa penjelasan tentang fungsi tradisi Aurodan cirebon \\
& yang sangat penting dalam kehidupan sosial dan dapat diangkat sebagai \\
& salah satu warisan budaya Cirebon yang memiliki ciri khas sebagai budaya \\
& khas pesantren yang menjaga kelestarian budaya dan kearifan lokalnya.
\end{tabular}

\begin{tabular}{ll}
\hline Article Info & ABSTRACT \\
\hline Article history: & The Aurodan tradition which is held by Jamaah Tarekat Asy-Syahadatain \\
Received: & in Cirebon is part of an oral tradition in the form of a ritual performance, \\
8 May 2020 & which is a dhikr that sounds loud along with the singing of the Cirebon \\
Revised: & nadhoman poetry. Aurodan reflects the soft, open and tolerant culture of \\
24 June 2020 & Cirebonese Islam as an acculturation product of several cultures, namely \\
Accepted: & Javanese, Sundanese, Arabic, and even other cultures in Cirebon. This \\
22 July 2020 & study aims to describe the function of the Aurodan oral tradition of the \\
Keyword: & Jamaah Asy-Syahadatain community in Cirebon. This research is a \\
Oral Tradition, & qualitative study that examines objects in natural conditions, to find \\
Aurodan, function, Asy- & meaning and generalization, where the researcher as the main instrument \\
Syahadatain Cirebon & uncovearch methods. This study was designed to describe, analyze, \\
& Cirebon tradition. This study uses basic data that is the function of \\
& $\begin{array}{l}\text { Aurodan Asy-Syahadatain Cirebon oral tradition. data collection technique } \\
\text { is conducted by observation, interview, document study. The results of this }\end{array}$ \\
& study found several explanations about the function of the Aurodan \\
cirebon tradition which are very important in social life and can be & appointed as one of Cirebon's cultural heritages that has a characteristic as \\
\hline
\end{tabular}


a typical pesantren culture that preserves its cultural preservation and local wisdom.

\section{PENDAHULUAN}

Masyarakat tradisional Cirebon di pesisir utara Pulau Jawa kaya akan tradisi lisan redundansi . Tradisi lisan itu menjadi warisan budaya yang mengandung nilai-nilai luhur. Tradisi lisan mencakup segala hal yang berhubungan dengan sastra, bahasa, sejarah, biografi, dan berbagai pengetahuan serta jenis kesenian lain yang disampaikan dari mulut ke mulut (Dwija, 2013).

Tradisi lisan dan wacana adalah istilah yang dapat dipertukarkan: mereka merujuk segala bentuk komunikasi, baik verbal maupun nonverbal, yang dilakukan orangorang dari suatu budaya anggap penting untuk diingat, dan bentuk yang mereka ajarkan anak-anak.

Tradisi lisan dan wacana hampir istilah yang menyerupai maknanya yakni sama-sama bentuk komunikasi namun masing-masing berbeda karakteristiknya sehingga beberapa pakar mengatakan wacana adalah tubuh yang besar dari tradisi lisan. Wacana adalah tubuh tradisi lisan yang terakumulasi dari verbal dan komunikasi non-verbal selama beberapa generasi, dan dapat disebut sejarah (Denoon, 2017). Folklore dan tradisi lisan adalah bagian integral dari budaya apa pun (Naqui, 2019).Tradisi Aurodan atau sering disebut dengan istilah tawasulan atau yahadian adalah salah satu tradisi yang dilakukan oleh masyarakat muslim tradisional di Cirebon yang mengikuti tarekat Jamaah Asy-Syahadatain, yang juga merupakan bagian dari tradisi yang berkembang di Pondok Pesantren Tradisional di Cirebon. Tradisi ini adalah salah satu ritual yang dilakukan untuk memohon keselamatan dengan cara berdoa, zikir, bersholawat, dan melantunkan puji-pujian berupa puisi nadoman yang berbahasa Cirebon secara bersama-sama, dengan gerakangerakan dan aturan tertentu. Tradisi ini memiliki banyak fungsi dan manfaat dalam kehidupan masyarakat di zaman dulu, terutama dalam bidang edukasi agama, pembentukan moral, dan meningkatkan kepekaan sosial dan kerja sama antar anggota masyrakat. Akan tetapi, pada kenyataannya, tidak semua anak dalam keluarga Jamaah Tarekat Asy-Syahadatain Cirebon menjalankan tradisi ini dalam kehidupan sehari-harinya bahkan sebagian mereka sudah tidak memahami cara melakukan tradisi ini.

Penelitian ini difokuskan pada pengungkapan fungsi-fungsi tradisi Aurodan yang dapat dimanfaatkan oleh masyarakat Jamaah Tarekat AsySyahadatain Cirebon. Ini dianggap penting mengingat tradisi lisan memiliki beberapa fungsi penting di masyarakat. Tradisi lisan mempunyai empat fungsi penting di masyarakat, yakni: (1) sebagai sistem proyeksi (projective system) yakni alat pencerminan angan-angan suatu kolektif; (2) sebagai alat legitiminasi kebudayaan; (3) sebagai alat pendidikan (paedagogik device); dan (4) sebagai alat pemaksa dan pengontrol agar norma-norma masyarakat akan selalu dipatuhi 
anggota kolektifnya (Danandjaja, 2007).

Studi tentang tradisi lisan Aurodan sangat penting untuk dilakukan sebagai upaya untuk melestarikan budaya dan memperkuat nilai-nilai kearifan lokal. Di era disrupsi memudahkan untuk penyebaran folklor ke masyarakat bahkan dunia internasional. Sehingga budaya Nusantara masih dapat menjadi sarana yang kuat di tengah pergaulan dunia yang semakin mengglobal (Purnomo, 2019). Tujuan dari penelitian ini adalah untuk mengungkap fungsi tradisi Aurodan yang dilakukan oleh komunitas Jamaah Tarekat Asy-Syahadatain Cirebon. Penelitian terkait tradisi ini diharapkan dapat menjadi sarana memperkuat budaya yang ada di Cirebon, khususnya tradisi lisan yang berkembang di lingkungan pondok pesantren tradisional yang jarang diperhatikan.

Tradisi Aurodan memiliki fungsi yang dimiliki karya sastra lisan. Hal itu dikarenakan di dalam tradisi Aurodan terdapat pelantunan bacaan puisi nadoman berbahasa Cirebon yang merupakan karya sastra lisan yang memiliki fungsi keindahan. Fungsi karya sastra lisan sama seperti karya sastra yang lain yakni "utile" dan "dulce", menyatukan dua unsur sifat yakni "bermanfaat" dan "yang enak, dan indah". Seni Sastra haruslah memiliki bentuk dan struktur fisik yang indah, menarik, bagus, dan penuh pesona sehingga memberikan kesenangan dan memiliki kandungan (struktur mental) yang memiliki nilai kemanfaatan untuk manusia dalam sebuah masyarakat (Teew, 1984).

Ada enam fungsi sastra bagi manusia apabila manusia mempelajari karya sastra dengan sungguh-sungguh, yaitu fungsi untuk hiburan, fungsi menyuguhkan estetika, fungsi memberikan pendidikan, fungsi mengasah kepekaan batin atau sosial, fungsi penambah wawasan dan pengetahuan, dan juga fungsi pengembangan kepribadian (Santosa, 2003).

\section{METODE}

Pendekatan kualitatif dengan metode etnografi adalah metode penelitian yang digunakan dalam penelitian ini untuk mendeskripsikan budaya dan cara hidup dari sudut pandang pelakunya. Etnografi memberikan petunjuk bagi peneliti dalam mendeskripsikan kebudayaan (dan masyarakatnya) berdasarkan apa yang ada dan terjadi di tempat kebudayaan itu berada (lapangan) (Heriyawati, 2016). Dengan menggunakan metode ini, peneliti mencoba untuk mendeskripsikan, menganalisis, dan menafsirkan pola perilaku, keyakinan, dan bahasa yang digunakan bersama oleh kelompok budaya yang berkembang dari waktu ke waktu (Creswell, 2002). Penelitian ini dilakukan di Desa Munjul dan Desa Pamuragan yang terletak di kabupaten Cirebon. Pemilihan kedua Desa tersebut sebagai tempat penelitian dengan alasan karena masyarakat di daerah tersebut masih menjalankan tradisi Aurodan yang biasa disebut dengan istilah tawasulan atau yahadian. Observasi partisipatif, wawancara, dan dokumentasi adalah teknik yang digunakan untuk mengumpulkan data penelitian.

Teknik analisis data yang dilakukan dalam penelitian ini menggunakan teknik analisis data Spradley. Teknik ini mencakup beberapa teknik yang dilakukan secara bertahap yaitu teknik analisis domain, 
analisis taksonomi, analisis komponen, dan analisis tema budaya (Spradley, 2016). Penggunaan analisis domain agar memdapatkan beberapa deskripsi umum dan komprehensif dari objek penelitian yang berupa tradisi Aurodan ini. Analisis taksonomi merupakan teknik analisis data yang menghasilkan deskripsi dari domain yang dipilih agar mendapatkan gambaran yang lebih detail untuk menentukan struktur internal dari tradisi Aurodan. Teknik analisis komponen digunakan untuk memperoleh dan memahami dari sifatsifat spesifik di setiap struktur internal dengan membedakan elemen yang ditemukan dalam tradisi Aurodan. Teknik analisis tema budaya untuk mencari hubungan antara domain dengan keseluruhan, menuliskannya sesuai tema tertentu dalam bentuk fokus dan sub-fokus penelitian.

\section{HASIL DAN PEMBAHASAN}

Setelah dikumpulkan data tentang tradisi Aurodan Jamaah tarekat AsySyahadatain yang diperoleh dari wawancara dan observasi langsung. Kami menemukan beberapa fungsi dari tradisi Aurodan, yaitu sebagai berikut.

\section{Fungsi Estetis \\ Keindahan}

Tradisi Aurodan memiliki fungsi estetis terutama untuk keindahan dalam melantunkan doa, zikir, dan puisi nadom yang berisi pesan-pesan moral. Puisi nadom memiliki aspek keindahan karena memiliki strukur layaknya sebuah puisi yang bersajak dan berirama.

Bentuk keindahan itu terlihat dari formasi partisipan tradisi Aurodan yang melingkari kain putih dan gerakan yang dilakukan reflek dengan satu komando disertai zikir dan berpuisi nadoman yang diucapkan bersama-sama dengan suara keras. Keindahan juga terdapat pada puisi nadoman yang dibacakan bersamasama, yang memiliki pola dan keindahan dalam susunan katanya, sehingga menyerupai sebuah lagu.

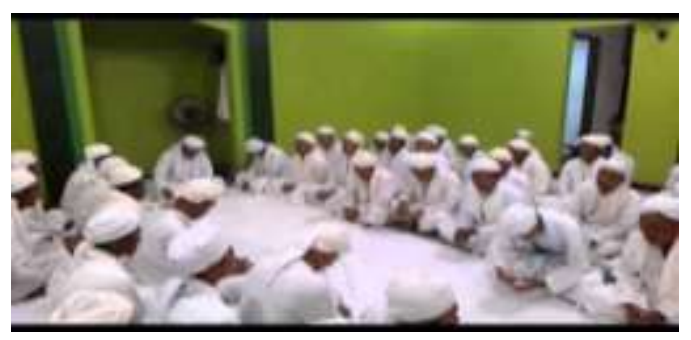

Gambar 1 Formasi Melingkar Tradisi Aurodan

Muhaiminan barisane ingkang
lempeng
Muhaiminan barisane ingkang
lempeng
eling Allah Rosululloh ingkang
mancleng
eling Allah Rosululloh ingkang
mancleng
mancleng ati rasa obah sing
Pangeran
mancleng ati rasa obah sing
Pangeran
mata ningal Rosululloh ning
adepan
mata ningal Rosululloh ning
adepan

Pola puisi nadoman dalam tradisi Aurodan seperti yang di atas, sangatlah indah bentuknya, memiliki rima,irama, dan metrum yang indah sehingga menjadikan tradisi Aurodan memilki daya tarik dari segi keindahan syair doanya yang berbentuk puisi yang dibacakan bersama-sama.

\section{Fungsi Pragmatis}

\section{Pedoman Keagaman}

Tradisi Aurodan sebagai tradisi yang memberikan banyak nilai 
pendidikan beragama yang bisa menjadi pedoman hidup dalam bermasyarakat dan berketuhanan. Tradisi Aurodan berisi pesan dari leluhur, berupa pedoman keagamaan yang berasal dari kitab aurod yang ditulis oleh ulama dahulu yang berisi puisi nadoman berbahasa Cirebon yang digunakan untuk berdakwah Islam.

Berikut kutipan puisi nadoman yang syarat akan nilai keagamaan.

Nure Kanjeng Nabi kang bagi Kanjeng Nabi; nure Kanjeng Nabi kang bagi Kanjeng Nabi; yen kebagi bagen mlarat tetep sugih; yen kebagi bagen mlarat tetep sugih; kang aran sugih, bunga susah eling Allah; kang aran sugih, bunga susah eling Allah; serta manut parentae Rosulullah; serta manut parentae Rosulullah.

Arti dari puisi nadoman di atas yaitu: cahaya kanjeng Nabi yang bagi Kanjeng Nabi; cahaya kanjeng Nabi yang bagi Kanjeng Nabi; bila terbagi walau miskin tetap kaya; bila terbagi walau miskin tetap kaya; yang namanya kaya, susah senang ingat Allah; yang namanya kaya, susah senang ingat Allah; serta menuruti perintah Rosulullah; serta menuruti perintah Rosulullah.

Maksud dari puisi nadoman ini adalah menjelaskan tentang konsep kekayaan yang tidak berpusat pada kepemilikan materi berupa harta dan benda. Konsep kekayaan menurut ajaran tarekat ini adalah ketaqwaan dan ketaatan, walau pun dalam keadan senang atau susah, sehingga kebahagian tidak bergantung pada materi, tapi bergantung pada Allah yang selalu dalam ingatan dan hati manusia yang kaya. Konsep ini membuat manusia lebih kuat dalam menjalani hidup, dalam kondisi apa pun tetak bersyukur dan selalu mengingat dan beribadah kepada Allah.

\section{Kebutuhan Naluri Manusia}

Tradisi Aurodan menjadi solusi bagi setiap individu untuk memenuhi kebutuhan batinnya dalam mendekatkan diri kepada sesuatu yang baik, mengevaluasi diri, membersihkan hati, serta membuang sifat-sifat buruk dalam diri seseorang. Tradisi Aurodan ini membuat batin seseorang lebih tenang, sabar, tidak mudah marah, dan tabah dalam menjalani permasalahan dalam hidupnya.

\section{Keutuhan Struktur Sosial}

Tradisi Aurodan memiliki fungsi untuk menjaga keutuhan struktur sosial dalam kehidupan bermasyarakat. Tradisi ini menyatukan beberapa individu agar mau duduk bersama, berdampingan, saling bergotor-royong, saling mendoakan, menjaga komunikasi dan interaksi sosial, sehingga menjadi masyarakat yang bersatu dan memiliki rasa saling menyayangi satu sama lain sehingga bisa menjaga persatuan dan keutuhan struksur sosial yang ada.

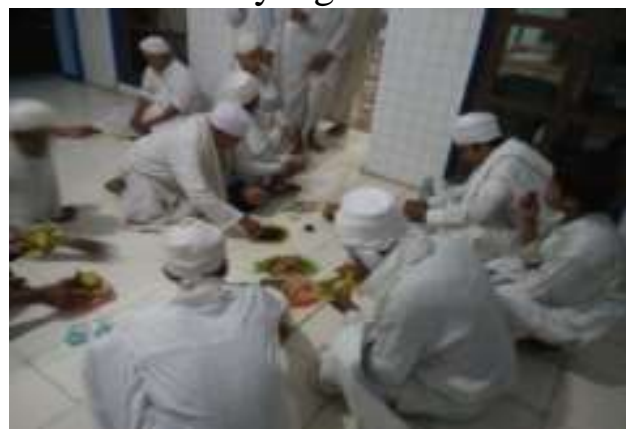

Gambar 2 Makan Bersama dalam Tradisi Aurodan 


\section{Solidaritas suatu Kolektif}

Tradisi Aurodan meningkatkan solidaritas setiap individu yang merupakan bagian dari komunitas jamaah taerekat Asy-Syahadatain. Tradisi ini juga diisi dengan pesanpesan yang mengarahkan umat untuk menjadi satu barisan yang lurus, yang solid, dan saling membantu satu sama lain, dalam mecari sebuah hidayah dan petunjuk dari tuhan yang Maha Kuasa.

\begin{tabular}{|c|c|c|}
\hline $\begin{array}{l}\text { Muhaiminan } \\
\text { lempeng }\end{array}$ & barisane & ingkang \\
\hline $\begin{array}{l}\text { Muhaiminan } \\
\text { lempeng }\end{array}$ & barisane & ingkang \\
\hline $\begin{array}{l}\text { eling Allah } \\
\text { mancleng }\end{array}$ & Rosululloh & ingka \\
\hline $\begin{array}{l}\text { eling Allah } \\
\text { mancleng }\end{array}$ & Rosululloh & in \\
\hline
\end{tabular}

Arti dari puisi nadoman di atas adalahMuhaiminan barisannya yang lurus; Muhaiminan barisannya yang lurus; ingat Allah Rosulullah yang kuat; ingat Allah Rosulullah yang kuat. Maksud dari puisi ini adalah, bahwa kita harus menyatukan pandangan dan meluruskan barisan kita untuk bersama-sama menguatkan keimanan dan ketaqwaan. Konsep amar maruf nahi munkar, yaitu kosep mengajak ke arah kebaikan dan mengingatkan untuk menjauhi yang buruk merupakan bentuk perwujudan ajakan untuk solidaritas kolektif para pelakunya.

\section{Pelarian dari Dunia Nyata}

Tradisi ini bisa menghilangkan kesedihan dan keresahan yang kita alami di kehidupan kita sehari-hari. Sehingga bisa dikatakan tradisi Aurodan ini bisa menjadi sebuah pelarian anggotanya ketika mereka menghadapi berbagai permasalahan dengan berharap mendapatkan cahaya petunjuk dari Tuhan Yang Maha Kuasa dan Juga dari Nabi Muhammad sebagai Rasul-Nya.

\section{Pencarian Dana Sosial}

Tradisi Aurodan juga bisa digunakan untuk media pencarian dana sosial, misalnya dana untuk pembangunan tempat ibadah, bantuan untuk korban bencana alam yang berasal dari sebagian uang jamaah yang bersedia memberi bantuan sosial.

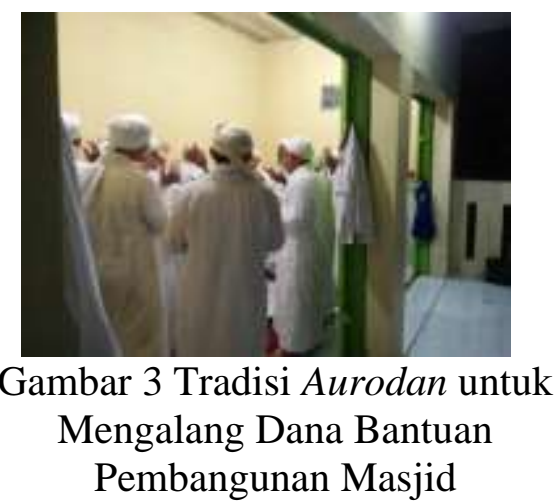

\section{Penerangan}

Tradisi Aurodan ini digunakan sebagai media dakwah yang berusaha mengedukasi masyarakat untuk memahami agama melalu puisi nadom dan pidato yang kadang diletakan di awal atau di tengah-tengah ritual Aurodan bersama.

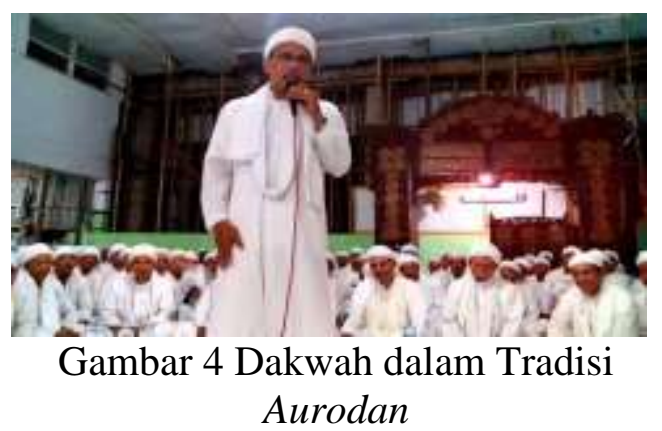

\section{Sumber Pengetahuan dan Kebijaksanaan}

Tradisi Aurodan juga menjadi sumber pengetahuan agama, karena dalam tradisi ini di dalamnya dilantunkan puisi nadom berbahasa Cirebon, yang syarat akan ajaran 
agama yang bersumber pada ajaran alQuran dan Al-Hadits.

\section{Fungsi Etis}

\section{Alat Pendidikan}

Sebagai alat dan media pendidikan agama bagi masyarakat, karena melalui tradisi ini masyarakat selalu diingatkan tentang ajakan dan anjuran untuk melakukan kebaikan, diingatkan tentang hakikat kebahagian dalam kehidupan manusia dari sisi agama, dingatkan juga tentang hari akhir, sejarah para nabi dan ilmu agama yang lain.

\section{Pengendali Prilaku Manusia}

Tradisi Aurodan berusaha mengendalikan prilaku masyarakat untuk berbuat baik, membersihkan hati dari penyakit sombong, dengki, iri, malas bekerja, malas beribadah, putus asa, dan tidak berterima kasih atas pemberian tuhan. Berikut puisi nadoman yang mengajarkan sembilan cara mendekatkan diri kepada Allah dan Rasul-Nya.

Ya Allah Ya Rosulullah pasrah awak kula lan sa ahliahli kula sedaya, kula niat belajar ngelampahi perkawis ingkang sanga

1. Senunggal niat belajar tobat

2. Kaping kalih niat belajar Qona'ah

3. Kaping tiga niat belajar Zuhud

4. Kaping sekawan niat belajar Tawakkal

5. Kaping gangsal niat belajar Muhafadhoh al as sunah

6. Kaping nenem niat belajar Ta'allamul ilmi

7. Kaping pitu niat belajar ikhlas
8. Kaping wolu niat belajar Uzlah

9. Kaping Sanga niat belajar Hifdzul awqot.

\section{Fungsi Historis}

1. Pembentukan Identitas dan Peradaban

Tradisi Aurodan memiliki fungsi historis sebagai pembentuk identitas komunitas jamaah terekat AsySyahadatain yang rendah hati, tidak mudah berputus asa, berjiwa sosial, menyukai kebersihan, tidak mencintai dunia secara berlebihan, mencintai dan menjalankan sunah rosulnya, dan suka berzikir.

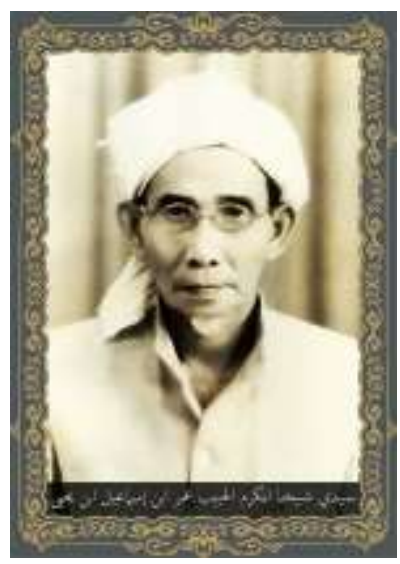

Gambar 5 Abah Umar Bin Ismail Bin Yahya Guru Tarekat dan Pendiri AsySyahadatain Cirebon

\section{Pelestari Sistem Budaya}

Tradisi juga berfungsi sebagai pelestari sistem budaya dalam membacakan doa secara bersamasama, bersuara keras, dan mendoakan dengan bertawassul. Pelestarian budaya Cirebon juga kental di sini, terutama sistem budaya islam yang dikembangkan oleh para wali songo, penyebar agama islam di tanah jawa. Penggunaan puisi nadom merupakan bentuk pelestarian metode dakwah para wali dengan lantunan puisi 
berbahasa daerah yang dinyanyikan namun di dalamnya terkandung ajaran agama islam. Nadom ini adalah puisi yang digunakan untuk menyebarkan ajaran agama islam saat masyarakat Cirebon dan Jawa pada umumnya masih buta huruf, sehingga media kitab berbahasa arab sulit untuk digunakan untuk mengajarkan ajaran islam, dan puisi nadom ini menjadi media yang paling cocok karena masyarakat bisa belajar agama islam melalui puisi berbahasa daerah yang dibacakan seperti lagu yang mudah dicerna dan diingat.

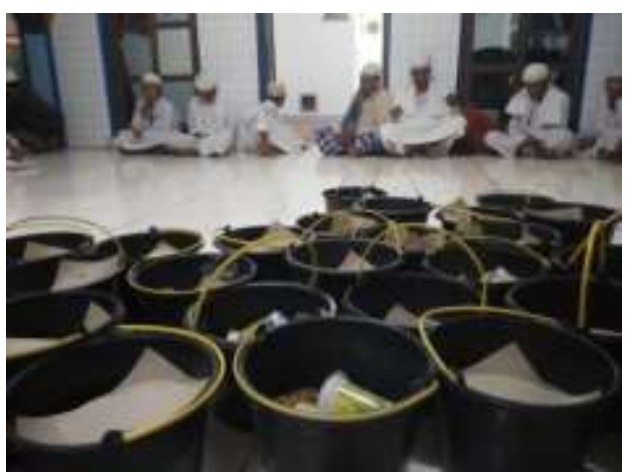

Gambar 6 Tradisi Tahlil dan Nasi

Berkat dalam Tradisi Aurodan

Warisan Leluhur (Wali Songo)

\section{PENUTUP}

Tradisi Aurodan ternyata memiliki beberapa fungsi bagi komunitas pemakainya yaitu sebagai berikut.

a. Fungsi estetis yaitu untuk keindahan

b. Fungsi pragmatis yaitu terdiri dari fungsi sebagai pedoman keagaman; kebutuhan naluri manusia; keutuhan struktur sosial; solidaritas suatu kolektif; pelarian dari dunia nyata; pencarian dana sosial; penerangan ; sumber pengetahuan dan kebijaksanaan.

c. Fungsi etis yaitu terdiri dari fungsi alat pendidikan; pengendali prilaku manusia. d. Fungsi Historis yaitu fungsi untuk pembentukan identitas dan peradaban; pelestari sistem budaya.

Semua fungsi itu menjadikan tradisi ini memiliki kebermanfaatan yang besar bagi jamaah tarekat AsySyahadatain sehingga patut dipertahankan.

\section{DAFTAR PUSTAKA}

Creswell, J. W. (2002). Educational research: Planning, conducting, and evaluating quantitative (pp. 146-166). Upper Saddle River, NJ: Prentice Hall.

Danandjaja, J. (2007). Folklor Indonesia: Ilmu gosip, dongeng, dan lain-lain. Jakarta: Grafiti.

Denoon, D., \& Lacey, R. (2017). Oral tradition in Melanesia. Port Moresby, PNG: University of Papua New Guinea.

Dwija, N. (2013) Mitos i ratu ayu mas manembah: Pendekatan theoantropologi (Folklor Nusantara: Hakikat, bentuk, dan fungsi). Yogyakarta: Ombak.

Heriyawati, Y. (2016) Seni pertunjukan dan ritual. Yogyakarta: Ombak

Naqvi, S., \& Khan, A. (2019). Multiple Intelligences Theory Applied to Folklore in Omani EFL Teaching. In Handbook of Research on Curriculum Reform Initiatives in English Education (pp. 52-67). IGI Global. 
Purnomo, A. D., \& Masdiono, T. (2019) Menggali Khasanah Tradisi Lisan ke Dalam Medium Visual Folklor Sunda Sebagai Sumber Ide Buku Seni (Artist's Book). In Seminar Nasional Seni dan Desain 2019 (pp. 47-53). State University of Surabaya.
Santosa, Puji et al. (2003). Materi dan Pembelajaran Bahasa Indonesia SD. Jakarta: Universitas Terbuka.

Spradley, J. P. (2016). Participant observation. Waveland Press.

Teeuw, A. (1984). Sastra dan Ilmu Sastra: Pengantar Teori Sastra. Jakarta: Pustaka Jaya. 